\title{
Computer Assisted Language Learning (CALL) Activities and the Students' English Oral Proficiency
}

DOI: https://doi.org/10.47175/rielsj.v2i3.301

\section{| Zaida K. Ulangkaya |}

\author{
Mindanao State University- \\ Maguindanao, Philippines \\ *zkulangkaya@msumaguindanao. \\ edu.ph
}

\begin{abstract}
The study aimed to determine the impact of Computer Assisted Language Learning Activities to the oral English Proficiency of JEEP 1 students. The students' pre and post mean scores were compared to determine the significant improvement in their oral English proficiency. This research made used of the experimental research design with pre and post-test design with 58 randomly selected students from different year levels who were enrolled at Mindanao State University- Maguindanao and currently taking the subject JEEP 1 of the S.Y. 2014-2015. The instrument used covered four specific areas as Sentence Reading, Reading and Pronunciation, Comprehension and Structure, and Sentence Repetition. The following are the summary of the findings: 1. Before the CALL Activities in JEEP 1, the students' oral English proficiency is lower elementary as indicated by the mean of 0.60; After engaging to the CALL Activities, the students' oral English proficiency is still lower elementary as proven by the mean score of 0.79; and After comparing the results, it was found out that there is a substantial transformation in the students' oral English proficiency level before and after Computer Assisted Language Learning Activities in JEEP 1 as indicated by the $t$-Value of 2.84 . Based on the results of the study, it was determined that CALL Activities have contributed slight improvement to the student's oral English proficiency score. However, the said activities did not improve their oral English proficiency level possibly due to some unknown factors that might have affected them during the duration of the study.

KEYWORDS

CALL Activities; English Proficiency; DynEd Software
\end{abstract}

\section{INTRODUCTION}

Learning through computer assisted language aimed at helping students use the language effectively for real life purposes. Students must be aware of the essential use of English language to become efficient in professional, academic and social settings. In a research conducted in the Philippines, English proficiency is found out to be declining. As shown in a language test result by IDP Education Pty. Ltd. Philippines, an accredited group that administers the International English Language Testing System (IELTS) to Filipinos looking for a job abroad showed that the country is experiencing challenge in terms of language proficiency and it carried upsetting impression to the country's linkages of job benefactors such as job-providing industries locally and internationally. To address the concern Philippine government urged the Department of Education to strengthen the effort in delivering an educational system that will strongly advance student's mastery in English. Therefore, numerous progressions and working shifts are made to make people around the 
globe become internationally competitive. One of the methodological shifts is the Computer Assisted Language Learning (CALL) which is both exciting and frustrating as a field of research and practice. It is exciting because it is intricate, lively, and rapidly changing, and it is exasperating for the same reasons.

Technology adds scopes to the complex domain of second language learning, demanding new knowledge and skills for those who wish to integrate it into their professional training or understand its effect on the language teachers and learners.

Computer Assisted Language Learning (CALL) is frequently professed, somewhat hardly, as a tactic to language coaching and knowledge in which the computer is used as an assistance to the exhibition, strengthening and valuation of material be cultured, usually including to an extensive collaborative component. Levy (1997) defines CALL more concisely and more approximately as the search for and study of applications of the computer in language teaching and learning. Levy's description is in contour with the assessment held by the mainstream of current CALL experts.

Inclusive of the Computer Assisted Language Learning is the JEEP or Job Enabling English Proficiency which is one of the programs introduced by GEM-USAID to aid the development of college students in Mindanao in terms of English proficiency for their future endeavor. In 2010, the program was introduced in Mindanao State UniversityMaguindanao. It is stated in its goal that this intervention provides resources that allow students from higher education institutions in Mindanao to acquire English language skills required for prolific engagement to those sectors demanding advanced expertise in the language. In addition, another purpose of JEEP is to enhance students' English proficiency to be an effective communicator. Language proficiency includes oral (listening and speaking) and written (reading and writing) mechanisms (Hargett, 1998, as cited in Talicop, 2009). This particular program has so many topics that promote the development of the students' four basic macro skills in English namely; reading, writing, listening and speaking. The JEEP 1 program focuses on students' listening and speaking enhancement utilizing software provided by Interactive Language Solutions (ILS) which is the DynEd Computerized Language Instruction. It has Interactive Multi-Sensory Input, Regular Assessment and Record Keeping and Simple Interface.

They say that despite the aids in English statement, the Philippines had a long way to go before it can ponder itself universally competitive in Business English proficiency. Some predictors noted that any noteworthy enhancements in the country's business English proficiency may invite more service-oriented investment. Meanwhile, there remained a large industry with pool of English language speaker, particularly English as second language. In filtering these skills within the personnel could support the beginning of the growth of the job predictions for young people in the country.

However, the breach amid typical English and Filipino English remained a challenge for the country and even in the small community such as in MSU-Maguindanao where the researcher conducted the study. It was observed that many of the students were having trouble in speaking the English language, they were more confident speaking their native language most of the time. They find speaking English language awkward.

Since the Job Enabling English Proficiency is presented in Mindanao State UniversityMaguindanao students to level up students' English skill, the researcher as an English coach and JEEP coordinator wanted to find out the contributions of JEEP as one of the Computer Assisted Language Learning to student's verbal English proficiency.

This study intended to find out the Effects of CALL activities to students' English Oral Proficiency level at Mindanao State University-Maguindanao during the S.Y. 2014-2015.

Unambiguously, the training hunted the responses of the following questions: 
1. What is the students' oral English proficiency level before the Computer-Assisted Language Learning Activities are introduced in their JEEP 1 class?

2. What is the students' oral English proficiency level after the Computer-Assisted Learning Activities are introduced in their JEEP 1 class?

3. Is there significant differences between the students' English proficiency level before and after the Computer Assisted Learning Activities were introduced in their JEEP 1 class?

\section{Research Hypothesis}

This research aimed to test the null hypothesis below:

$\mathbf{H}_{\mathbf{0}}$ : There is no significant difference between the students' English oral proficiency level before and after the CALL were introduced in JEEP 1.

\section{RESEARCH METHODS}

The researcher used the experimental method with pre and post-test design to find out the effects of CALL Activities through JEEP 1 course to the Oral English Proficiency of 58 randomly selected students from different year levels who were officially enrolled at Mindanao State University Maguindanao and currently taking the course JEEP 1. The researcher used the Speaking Test of the DynEd software installed in the computer of the JEEP Laboratory as the instrument of the study in determining the oral proficiency of the students before and after the CALL Activities intervention. This test is designed to be used as a complement to DynEd's Placement Test. In addition to intelligible pronunciation, the sentence repetition items in each of the tests attempt to measure language "chunking" ability. From the RHR (Recursive Hierarchical Recognition) learning theory, the assumption here is that oral proficiency is proportional to chunking ability, which is the ability to automatically group words so that they can be processed in working, phonological memory. As it progresses, test items gets longer and more complex, thereby measuring chunking skill. In the higher-level speaking test (1.0-2.7+), if too many items are missed, the test will automatically stop.

The data was analyzed and interpreted using the descriptive statistics particularly the weighted mean, percentage and frequency. This process would determine the respondents' oral English proficiency before and after the CALL activities through JEEP 1. In finding out the significant differences in the students' oral English proficiency level before and after the CALL activities, t-test was utilized. The oral English proficiency of the students was described based on the level of description below:

0.0 Beginner

0.2 False Beginner

0.5 Basic Survival

0.7 Lower Elementary

1.0 Elementary

1.2 High Elementary

1.5 Advanced Elementary

1.7 Lower Intermediate

2.0 Intermediate

2.2 Higher Intermediate

2.5 Advanced Intermediate

2.7 Advanced with Confidence 


\section{RESULTS AND DISCUSSION}

\section{The Students' Oral English Proficiency level Before Computer-Assisted Language Learning Activities in JEEP 1}

The Table 1 shows the speaking test scores of the students. As shown on the Table, the highest scores of 2.5 got by the students which fall on the percentage rate of one point seventy-two (1.72). This shows that there is only one (1) out of the 58 subjects who is classified under the advanced intermediate level.

Table 1. Students' Oral English Proficiency Level Before CALL Activities

\begin{tabular}{llll}
\hline Range of Score & Frequency & Percentage (\%) & Description \\
\hline 0.0 & 16 & 27.59 & Beginner \\
0.2 & 5 & 8.62 & False Beginner \\
0.5 & 6 & 10.34 & Basic Survival \\
0.7 & 17 & 29.31 & Lower Elementary \\
1.0 & 7 & 12.07 & Elementary \\
1.2 & 3 & 5.17 & Higher Elementary \\
1.5 & 0 & 0.00 & Advanced Elementary \\
1.7 & 2 & 3.45 & Lower Intermediate \\
2.0 & 0 & 0.00 & Intermediate \\
2.2 & 1 & 1.72 & High Intermediate \\
2.5 & 1 & 1.72 & Advanced \\
2.7 & 0 & 0.00 & Advanced with high \\
& \multicolumn{3}{c}{ proficiency } \\
\hline Total & 58 & SD $=\mathbf{0 . 5 6}$ & \\
Mean $=\mathbf{0 . 6 0}$ & \multicolumn{2}{c}{ Lower Score: 0.0} & \\
\hline Highest Score: 2.5 & &
\end{tabular}

The highest score obtained by the students is really low than what is expected of a college student. This may be attributed to the fact that these students are disturbed by some personal related issues which made them out-of-focus.

The Table also shows that there are 16 or 27.89 percent of the file students who obtained the lowest possible scores classified under the score range of zero point zero (0.0) which is described as beginner. They are the students who belong to those who really need enhancement on their oral proficiency. They need to learn and practice more with their speaking skills through different spoken related activities.

Furthermore, the Table shows that 17 or 29.31 percent of the students have an oral proficiency of low elementary level. This implies that they can practice with short sentences to answer simple questions about job, family, daily and weekly schedule, likes and dislikes and weather but not about life history or future plans. The sentences in their utterances are short and fragmented which are only limited to basic patterns.

In totality, Table 1 reflects a mean of 0.60 which falls in the description of lower elementary. This connotes that before the CALL activities are introduced the students' oral English proficiency level is lower elementary. Hence, the students in general can only use short utterances to answer simple questions about job, family, daily and weekly schedule, likes and dislikes and weather but not about life history or future plans. Their sentences are short and fragmented and limited to basic pattern.

In developing oral English proficiency, it is not enough that the students would just be leaving everything into the four corners of the classroom. In support to the DynEd's provision, oral English proficiency can only be achieved by taming the ear and the tongue of students of the correct pronunciation and usage of words. CALL can be completed 
through learners; pace, pattern of responses and so on, and can alter the linguistic material to the requirements of the specific students (Ahmad et al, 1985).

\section{The students' Oral English Proficiency Performance Levels after Computer Assisted Language Learning Activities were introduced in JEEP 1}

The data presented in this section are the students' scores in speaking test after the CALL activities in JEEP 1. It shows the frequency and percentage of distribution of students' oral English proficiency.

Table 2. The Students' Oral English Proficiency Performance Levels after CALL Activities

\begin{tabular}{llll}
\hline Range of Score & Frequency & Percentage $\mathbf{( \% )}$ & Description \\
\hline 0.0 & 10 & 17.24 & Beginner \\
0.2 & 4 & 6.89 & False Beginner \\
0.5 & 7 & 12.07 & Basic Survival \\
0.7 & 15 & 25.86 & Lower Elementary \\
1.0 & 13 & 22.41 & Elementary \\
1.2 & 2 & 3.45 & Higher Elementary \\
1.5 & 1 & 1.72 & Advanced Elementary \\
1.7 & 0 & 0.00 & Lower Intermediate \\
2.0 & 2 & 3.45 & Intermediate \\
2.2 & 1 & 1.72 & High Intermediate \\
2.5 & 2 & 3.45 & Advanced \\
2.7 & 1 & 1.75 & Advanced with high \\
& & & proficiency \\
\hline Total & $\mathbf{5 8}$ & $\mathbf{1 0 0 . 0 0}$ & \\
Mean $=\mathbf{0 . 7 9}$ & & SD $=\mathbf{0 . 6 5}$ &
\end{tabular}

The oral English proficiency level of the students after CALL activities were introduced was gauged. In line with this, the data in Table 3 reflected the highest score within the score range of 2.7 labeled as advanced with high proficiency and it was obtained by only one student out of 58 subjects. The data justified that even after the students' exposure to CALL activities in JEEP 1 where they were provided varied speaking activities in the computer still only one of them can brand a prolonged performance and recapitulate the key point of the talk. In an advanced level with high proficiency, the students' terminology is huge enough where reliable resources such as newspapers and news programs can be understood without much struggle and can partake in chats with natural chatterers about eclectic variety of subjects. In this level the students can begin to use language to get involve in debate or other conversational activities which shall enhance their language skills.

The improved scores of the students are notable despite some whose scores got lower than their pre-test. These may be caused by technical problems encountered by some takers specifically the headsets they have used. The test normally includes some people who may have voice characteristics that are outside the limits for the technology to work well, so it needs to be used with care. Had it not been for this reason, their scores could have gotten even far better that their pre-test.

In the score range of 2.5 categorized as high intermediate only 2 of 58 students have obtained this score after CALL activities. The result explains that out of 58 students only 2 
have the ability to stretch vibrant commands and enlightenments with qualified skill. These 2 students can discuss news and current events, though with difficulty due to vocabulary confines and some proficiency limitations. They can also participate in most business situations and meetings, in most cases without assistance.

In addition, only 1 or 1.75 percent out of 58 students scored 2.2 which are described as intermediate. This means that only one student can handle complex information of a general nature or in range of specification, however, there are some blunders in grammar that causes misperception. In the same way, this student if given time to prepare can stretch vibrant appearance summary. This student can also use proper phrases in social encounters for most situations including the problem solving.

In the score of $2.0,2$ or 3.45 percent of the students have garnered this score with a description of low intermediate. Meaning, they can direct abstract ideas such as possibilities, even with frequent errors in grammar and few vocabularies that is still too narrow to discuss.

Furthermore, it is reflected in Table 3 that no one got the score of 1.7 with a description of low intermediate. This indicates that none from the 58 students can express abstract ideas, such as supposition, though with frequent errors in grammar with narrow vocabulary that hinders them to discuss news and current events without difficulty and confusion.

In the entire Table 3, the students oral English proficiency level bas a mean of 0.79 which falls in between 0.7 to 1.0, since the figure is closer to 0.7, the students' oral English proficiency level after CALL are introduced in JEEP 1 class is described lower elementary.

This mean that the students can use quick response for simple questions about job, family, daily and weekly schedule, like and dislikes and weather. They can only use brief or uneven sentences limited to everyday thing, places or business and basic needs. The data imply that even after the students were exposed to varied CALL activities, they still need rigorous instruction on oral communication to further enhance their oral English proficiency level. Other unknown factor may have affected the outcome of the study. This concurs to the idea that extra attention should also be certain to students on they use computers on their own and what drill and process could help them to be more successful (Blin, 2004; Schwienhorst, 2008)

\section{The difference in the Speaking Test Scores before and after CALL Activities in JEEP 1}

The data presented in this section are the total number of the subjects, the algebraic sum of the difference between the speaking test scores before and after CALL, the algebraic sum of the square of the difference between the speaking test scores before and after CALL, and Computed t-value before and after the CALL activities were introduced in JEEP 1.

The data in Table 1 clearly manifested a mean score of 0.60 as initial mean score of the students the speaking test with an SD of 0.56. The students' mean score in speaking test increased as reflected by a mean score of 0.79 with an SD of 0.65 . The difference in the mean scores of the paired variables was verified through the t-test and it revealed that the difference is significant as indicated as the $t$ value of 2.84 that is higher than the tabular value of 1. 68. The data indicated a significant improvement in the students' data proficiency level after exposing them to CALL activities in their JEEP 1 class.

This indicates that the students can perform basic tasks on simple interactions and conversations. The improvements in the students' scores can also be attributed to the repeated sessions and working hours allotted by a particular student. Repeating and recording as one of the tasks in their computer related activities served as practice for the students which gradually exhaust them with the repeated use of English language that eventually increased their oral English proficiency level. 
Table 3. The Speaking Test Scores before and after the CALL were introduced in JEEP 1.

\begin{tabular}{cccccc}
\hline Paired Variable & $\mathbf{N}$ & $\sum \mathbf{D}$ & $\sum \mathbf{D}^{2}$ & $\begin{array}{c}\text { Computed t- } \\
\text { Value }\end{array}$ & Description \\
\hline Before & 58 & 11.0 & 16.88 & 2.84 & Significant \\
After & & & & & \\
\hline
\end{tabular}

Computed to be significant at 0.05 level should be at least 1.68 (one-tailed test) with $d f$ of 57 .

Legend:

$\mathrm{N}=$ = total number of subjects of the study

$\sum \mathrm{D} \quad=$ the algebraic sum of the difference between the speaking test scores before and

after the CALL Activities

$\sum \mathrm{D}^{2}=$ the algebraic sum of the square of the difference between the speaking test scores before and after the CALL Activities

The slight increase has also been attributed to the fact that these students have often heard accents of English native speakers on the activities given, since in the reality, employees do have choices on what kind of people they are going to interact with. Lee (2000) states that holding a computer-based instruction could aid students brace their language skills by completely stirring their learning attitude and by helping them figure self-instruction approaches and stimulate their self-assurance.

Therefore, null hypothesis stating that a significant difference between the students' English proficiency level for the pre and post CALL Activities is rejected.

\section{CONCLUSION}

It is concluded that Computer Assisted Language Learning Activities have contributed slight increase to the verbal skill level of the students who were beginners to CALL. However, the said activities did not improve the oral English skill level of the students who were already very much acquainted with the Computer Assisted Language Learning Activities in the case of Mindanao State University-Maguindanao.

\section{ACKNOWLEDGMENT}

To the people who have made my writing possible, my heartful gratitude. Many thanks to my paper adviser for the guidance and support, my co-faculty and family for the funding and even going out of the way to extend aid and backing me up all throughout to my students who served as my inspiration coming with the study and for working it out with me.

My gratefulness specially goes to the university I worked for the past 11 years. Mindanao State University-Maguindanao has been with me, the administration supported me and provided me all the assistance I can have to complete my paper.

\section{REFERENCES}

Ahmad, K., G. Corbett \& M. Rogers. (1985). Using computers with advanced language learners: an example. The Language Teacher.

Blin, F. (2004). CALL and the development of learner autonomy: Towards an activity theoretical perspective. ReCALL.

Growth with Equity in Mindanao Program. (2007). The Job Enabling English Proficiency (JEEP)Project.http://www.mindanao.org/?option=com_content\&view=article\&id=198 \&Itemd+266 
Lee, K. (2000). English Teachers' Barriers to the Use of Computer-assisted Language Learning. http://iteslj.org/Articles/Lee-CALLbarriers.html

Levy, M. (1997). Computer-assisted language learning: Context and conceptualization. Oxford University Press.

Growth with Equity in Mindanao Program. (2007). The Job Enabling English Pro $\square$ ciency (JEEP)Project. Retrieved on 22/02/2019 from http://www.mindanao.org/?option $=$ com_content $\&$ view $=$ article\&id=198\&Itemid+266.Growth with Equity in Mindanao Program. (2007). The Job Enabling English Pro $\square$ ciency (JEEP)Project. Retrieved on 22/02/2019 from http://www.mindanao.org/?option $=$ com_content $\&$ view $=$ article $\& i d=198 \&$ Itemid +266 .

Levy, M. (2002). CALL by design: Discourse, products and processes. ReCALL.

Levy, M. \& Stockwell, G. (2006). CALL dimensions: Options and issues in computer assisted language learning. Mahwah, $\mathrm{NJ}$ : Lawrence Erlbaum

Schwienhorst, K. (2008). Learner Autonomy and CALL Environments. Routledge.

Talicop, A. (2009). Oral Communication Level of the First Year BSE English Students at Mindanao State University Maguindanao (Undergraduate Research Project). Mindanao State University Maguindanao, Philippines. 